\title{
The future of financing for HIV services in Uganda and the wider sub-Saharan Africa region: should we ask patients to contribute to the cost of their care?
}

Tom Kakaire ${ }^{1}$, Walter Schlech ${ }^{2}$, Alex Coutinho ${ }^{1}$, Richard Brough ${ }^{1}$ and Rosalind Parkes-Ratanshi ${ }^{1 *}$

\begin{abstract}
Whilst multi-lateral funding for HIV/AIDS dramatically increased from 2004 to 2008, it has largely plateaued in the last 8 years. Across sub-Saharan Africa, up to $20 \%$ of total spending on health is used for HIV services, and of this over $85 \%$ is estimated to come from international funding rather than in-country sources. In Uganda, the fiscal liability to maintain services for all those who are currently receiving it is estimated to be as much as $3 \%$ of Gross Domestic Product (GDP). In order to meet the growing need of increased patient numbers and further ART coverage the projected costs of comprehensive HIV care and treatment services will increase substantially. Current access to HIV care includes free at point of delivery (provided by Ministry of Health clinics), as well as out-of-pocket financing and health insurance provided care at private for- and not for- profit facilities. The HIV response is funded through Ugandan Ministry of Health national budget allocations, as well as multilateral donations such as the President's Emergency Plan for AIDS in Africa (PEPFAR) and Global Fund (GF) and other international funders. We are concerned that current funding mechanism for HIV programs in Uganda may be difficult to sustain and as service providers we are keen to explore ways in which provide lifelong HIV care to as many people living with HIV (PLHIV) as possible. Until such time as the Ugandan economy can support universal, state-supported, comprehensive healthcare, bridging alternatives must be considered. We suggest that offering patients with the sufficient means to assume some of the financial burden for their care in return for more convenient services could be one component of increasing coverage and sustaining services for those living with HIV.
\end{abstract}

Keywords: Financing, Sustaining, Uganda, HIV, Treatment

\section{Background}

Since 1990, 458 billion United States dollars (USD) has been spent in development aid for health. This aid comes primarily from donor governments and philanthropic organizations. Of this, $23.2 \%$ was targeted for HIV/AIDs treatment and support [1]. Whilst multilateral funding for HIV/AIDS dramatically increased from 2004 to 2008 , it has largely plateaued in the last 8 years, with a drop in 2010 and marginal $1 \%$ increase from 2013 to 14 [2]. Across sub-Saharan Africa, up to $20 \%$ of total spending on health is used for HIV

\footnotetext{
* Correspondence: rp549@medschl.cam.ac.uk

${ }^{1}$ Infectious Diseases Institute, Makerere University College of Health Sciences,

PO Box 22418, Kampala, Uganda

Full list of author information is available at the end of the article
}

services, and of this over $85 \%$ is estimated to come from international funding rather than in-country sources [3]. Uganda is among 51 countries that rely on international sources to fund over $75 \%$ of their HIV response; over 20 donors contribute over USD 400 million annually [4]. There were an estimated 1,500,000 people living with HIV in Uganda in 2012 and by the end of June 2013 567,000 eligible persons were estimated to be receiving ART. Unfortunately despite the scale up of HIV services in Uganda, there is an increased HIV prevalence (from $6.8 \%$ in 2001 to $7.2 \%$ in 2012) and only $40 \%$ of people eligible for ART are currently receiving it [5]. Even at this level of ART coverage the fiscal liability for Uganda to maintain services for all those who are currently receiving it is estimated to be as much as 
$3 \%$ of GDP $[5,6]$. In order to meet the growing need of increased patient numbers and further ART coverage the projected costs of comprehensive HIV care and treatment services will increase substantially. Whilst this has been deemed to be cost effective in modeling in sub-Saharan African epidemics (Zambia, South Africa) expansion of ART coverage to those with CD4 counts over 350 cells/ul will still cost between $\$ 237$ to $\$ 1691$ per DALY averted [7]. Consequently the sustainability of these services is extremely uncertain, as international funding has plateaued and there is no clear long term plan for the Government of Uganda (GOU) to fill the potential gap. This is compounded by the growing view that HIV/AIDS care gets a disproportionate allocation of national health resources relative to other chronic conditions and that it should be "normalized" so that the financing model for HIV/AIDs more closely reflects the economic and social reality of Uganda. This article reviews the current literature on sources of HIV service financing in Uganda and the possible options to expand and sustain life-long HIV treatment in Uganda.

\section{Models of access to health care and HIV services in Uganda}

Table 1 summarizes the ongoing local financing models in Uganda. It describes the current status of these options mentioned above, and the action required from stakeholders to expand and strengthen these options.

\section{Free at point of delivery}

Following the abolition of user fees in Uganda in 2001 [8], health care at government clinics is free at the point of delivery, for a menu of selected services (mainly outpatient) and informal charging for additional add on services which are sometimes present. This could be termed a "publically provided health insurance" financed by taxes and other sources of government revenue. The Ministry of Health aim is to provide all necessary HIV/

Table 1 Future HIV financing options for PNFPs

\begin{tabular}{|c|c|c|c|}
\hline Option & Current status & Government action required & PNFP action required \\
\hline $\begin{array}{l}\text { Direct Government funding } \\
\text { of services and/or centralized } \\
\text { HIV/AIDS Fund }[2,6,10]\end{array}$ & $\begin{array}{l}\text { Inadequate resources and } \\
\text { inadequate budget allocation }\end{array}$ & $\begin{array}{l}\text { - Streamlined, transparent } \\
\text { public- private partnership } \\
\text { (PPP) frameworks for health } \\
\text { - Long term budget } \\
\text { commitment } \\
\text { - Engagement of donors for } \\
\text { medium term budget support } \\
\text { - Innovative tax/revenue collection } \\
\text { and allocation measures } \\
\text { - Stronger accountability and performance/ } \\
\text { quality measurement systems }\end{array}$ & $\begin{array}{l}\text { - Systems to meet minimum public } \\
\text { private partnership guidelines } \\
\text { - Less vertical /"silo" based programs } \\
\text { - Health system wide capacity building } \\
\text { - Quality Assurance and Performance } \\
\text { measurement systems }\end{array}$ \\
\hline $\begin{array}{l}\text { National Health Insurance } \\
\text { Scheme }[6,11,13]\end{array}$ & In discussion & $\begin{array}{l}\text { - Stakeholder involvement; generating } \\
\text { a consensus on nature and scope } \\
\text { of coverage } \\
\text { - Fund management capacity } \\
\text { - Governance, accountability and } \\
\text { confidence building } \\
\text { - Legislation and regulation }\end{array}$ & $\begin{array}{l}\text { - Definition and implementation of } \\
\text { systems to meet minimum NHIS } \\
\text { requirements for PNFP providers } \\
\text { - Capacity building for NHIS compliance } \\
\text { - Quality Assurance and Performance } \\
\text { measurement systems }\end{array}$ \\
\hline Out-of-Pocket Service & $\begin{array}{l}\text { Currently funds } 50 \% \text { of } \\
\text { health care [32] }\end{array}$ & $\begin{array}{l}\text { - Stronger accountability and performance/ } \\
\text { quality measurement systems } \\
\text { - Direct cash transfers }\end{array}$ & $\begin{array}{l}\text { - Quality Assurance and Performance } \\
\text { measurement systems }\end{array}$ \\
\hline Private Insurance $[16,17]$ & $\begin{array}{l}\text { Very low coverage, inadequate } \\
\text { regulation }\end{array}$ & $\begin{array}{l}\text { - Stronger Regulation } \\
\text { - Stronger accountability and performance/ } \\
\text { quality measurement systems }\end{array}$ & $\begin{array}{l}\text { - Creating an attractive business } \\
\text { proposition for private insurance firms } \\
\text { - Creating systems to meet minimum } \\
\text { private health insurance company } \\
\text { requirements }\end{array}$ \\
\hline $\begin{array}{l}\text { Community Health Insurance } \\
\text { Schemes [11] }\end{array}$ & $\begin{array}{l}\text { Very low coverage, inadequate } \\
\text { regulation }\end{array}$ & - Legislation and regulation & $\begin{array}{l}\text { - Community engagement and } \\
\text { confidence building } \\
\text { - Community accountability mechanisms } \\
\text { - Differentiated care for scheme members }\end{array}$ \\
\hline $\begin{array}{l}\text { Co-Payment to subsidize } \\
\text { overall costs of care }\end{array}$ & $\begin{array}{l}\text { Used mainly by faith based } \\
\text { organizations and NGOs, but } \\
\text { little documentation on } \\
\text { coverage and best practices }\end{array}$ & $\begin{array}{l}\text { - No additional legislation and/or } \\
\text { regulation }\end{array}$ & $\begin{array}{l}\text { - Creating capacity to manage and } \\
\text { report separate (paying and non-paying } \\
\text { client) income streams } \\
\text { - Mobilizing paying and non-paying } \\
\text { client support } \\
\text { - Mobilizing external stakeholder (eg } \\
\text { donor and government) support } \\
\text { - Maintenance of standard quality } \\
\text { care for all clients }\end{array}$ \\
\hline
\end{tabular}


AIDS services free in the 2655 government health facilities it owns and manages [9]. However, the total health allocation in the national budget fell from $8.3 \%$ in FY $2011 / 2012$ to $7.4 \%$ in FY 2012/2013 which means that the overall level of expenditure on health is significantly below the Abuja target of a $15 \%$ allocation of a government's budget to health [10], and finding sufficient funding for HIV and other health services is a challenge.

The GOU has taken some steps to introduce a National Health Insurance Scheme (NHIS) since 1995, but this has made little progress largely due to negative stakeholder influence [11]. Even if it was implemented, it's not clear how the NHIS in its current proposed form would incorporate existing health financing systems in order to avoid fragmentation and create mechanisms for cross-subsidization [12]. Moreover, feasibility studies generally point to public mistrust, as well as a lack of key systems and capacities (particularly relating to governance and accountability) to implement the NHIS scheme in Uganda which would need to be addressed [13].

\section{Out-of-pocket financing}

In addition to government clinic there are 994 private for profit (PFP) and 801 private not for profit (PNFP) (including faith based) health facilities, of varying quality, size and geographical distribution [9]. The 2010 National Health Accounts (NHA) Study in Uganda for health expenditures estimated that $50 \%$ of health expenditure came from private funds (42\% from households) [14]. Many people seek HIV services with a fee for service in PFP and PNFP facilities and factors associated with this include distance to service provided, perceived better quality of service and avoidance of long waiting times [15].

\section{Health Insurance}

Data on health insurance is challenging to come by. In 2004 WHO estimated $0.2 \%$ of total health expenditure was on private medical insurance [16]. Estimates from 2008 suggest that only $0.5 \%$ of the population in Uganda has any health insurance coverage [12]. Private health insurance schemes cover only $0.2 \%$ of the population and are largely available only for people in formal employment whose employers subsidize the cost [17]. The 30 registered community insurance schemes in Uganda are mostly health facility-based schemes in which premiums are paid by individual community members. These schemes cover only an estimated additional 100,000 people (about $0.3 \%$ of the current population) [8].

\section{Current Sources of funding and future options for HIV/AIDs services in Uganda Government funding}

In FY 2012/2013 the GOU spent $7.4 \%$ of its total annual budget on financing health systems, in particular human resources in the health sector, on which the delivery of HIV/AIDs services relies heavily. Of this only about $3 \%$ of the health budget is for targeted to HIV/AIDS programmes, but the remainder of this funding indirectly supports HIV programmes through government health systems strengthening. Policy innovations to increase the budget for health (and specifically for HIV services) are being considered such as an HIV tax on selected services and/or a cash transfers.

\section{The President's Emergency Plan for AIDS in Africa (PEPFAR) funding}

The United States government Presidents Emergency Fund for AIDS Relief (PEPFAR) funded programs invested over $\$ 1.8$ billion in HIV-related financing for Uganda between 2004 and 2011. PEPFAR currently contributes over $85 \%$ of the national HIV response through projects implemented by international and local organizations (PNFP organizations) which provide free HIV/ AIDS services or significantly support such services at public facilities. In practice, this means PNFPs housed within government health facilities, but running a siloed service, with directly employed health care workers but reporting to the national Ministry of Health system through the Health Information Management Service (HMIS). PEPFAR funding has already plateaued and PEPFAR now requires "cost-sharing assurances" from governments [18]. As governments assume more costsharing commitments, PEPFAR plans to more actively cede control over priority-setting and accounting for results to partner countries.

\section{Global Fund (GF) and other funders}

Since its inception, the Global Fund to Fight AIDS, Tuberculosis and Malaria (Global Fund) has disbursed over USD 230 million to support various aspects of HIV/ AIDS programs in Uganda through government and civil society mechanisms [19]. While the Global Fund has mainly utilized the mainstream government channels for delivering its support for the HIV effort, a substantial part of downstream resources that it provides (particularly ARVs) are delivered either directly through PNFPs or with significant support from PNFPs at government facilities [20]. The Global Fund has prioritized lower income, high burden countries and streamlined the funding application process through its new funding mechanism to make funding more predictable and flexible [21]. Nonetheless, developed country contributions to the Global Fund and other funding mechanisms are on a downward trend, triggering similar cutbacks in funding to many countries' HIV programs. This signals potential exposure to the risk of a serious financing gap particularly for PNFPs providing free HIV services to the public. 


\section{The case for voluntary co-pay: Can Ugandans help each other to pay for HIV care?}

A National Health Insurance scheme that integrates all available external, private and public providers and financing agencies would create the opportunity reduce administrative costs, create less fragmented, full service provision points, and provide the impetus for introduction of comprehensive cross-subsidized contributory financing for health in general and HIV services in particular. However, in reality this may not be developed in time to fill the gap between drop in multi-lateral donations and a definite government commitment to funding for HIV services. As PNFP we are front line providers of HIV care. As such our organization as well as others will feel the early effects of a reduction or plateauing in funding, and will be unable to expand our services further, or will need to cut back. We believe that the option that may be most expedient for PNFP providers such as ourselves to continue to provide care in the short term is development of voluntary co-pay services. Uganda has an improving economy with a rising middle class; the number of Ugandans in the middle class (defined as those whose ability to meet their basic needs is relatively stable and who can afford to save for the future) increased from 1.8 million 1992 to 12.6 million in 2012 (10 to $37 \%$ of the population) [22]. In Uganda the 2011 AIDS indicator survey found that HIV prevalence increases with higher socio-economic status [23], and many of these PLHIV will access care in the private sector due to reduced waiting times and longer opening hours. However, the private health sector which already charges a fee for service, is a profit making sector, which has no obligation to help the lower income strata. In addition, as they are independent of the government system there is no quality control on their care [24], records are often absent and retention in care is poor [25].

We suggest that as a short term measure to mitigate against the emerging risk of financing gaps, PNFPs could explore the introduction of voluntary co-pay schemes so that those who can afford pay for services that can help subsidize the cost for those who cannot afford to pay. However, previous experience with co-pay systems both within the general health service suggest that they may affect utilization of services, as in Uganda, their abolition in 2001 increase attendance at health clinics [26]. Of particular concern in HIV care is lack of adherence to ART drugs and development of drug resistance, which has been noted when patients are paying for care [27, 28].

Therefore, in order mitigate against these issues, and to maintain a reasonable level of equity, we propose that such schemes could differentiate services through convenience and accessibility, whilst maintaining essential services at an acceptable standard for both groups of clients. For example, patients pay a standard cost for consultation in order to see the same doctor at each appointment or to access care at weekends or evenings, but are not charged for tests or medication. At the Infectious Diseases Institute in Kampala we are currently studying the feasibility of this concept by piloting a copay component to our large, multidisciplinary HIV clinic. A routine customer care survey of 387 of our 8500 patients suggested that over $40 \%$ would be willing to pay a fee for greater convenience with longer (after work) opening hours and shorter waiting times. Qualitative research in our clinic has shown general acceptability of some patients for co-pay services for convenience, and also a willingness of those patients to contribute to the cost of care for other patients with less resources [29] and preliminary data suggests that access to a copay clinic improves retention to care in those who were lost to follow up within the private sector [30]. However, we will need to determine if this model is actually cost saving and can contribute funds to support sustaining of services, as previous experience with user fees in Africa suggest administration costs can be greater than fees collected [31].

\section{Conclusion}

We are concerned that current funding mechanism for HIV programs in Uganda is not sustainable and as service providers we are keen to explore ways in which provide lifelong HIV care to as many people living with HIV (PLHIV) as possible. In reality, it is likely that only a model that combines several different financing approaches will provide the necessary care and treatment for our PLHIV in the future. Until such time as the Ugandan economy can support universal, statesupported, comprehensive healthcare bridging alternatives must be considered. We suggest that offering patients with the sufficient means to assume some of the financial burden for their care in return for more convenient services could be one component of preparing for a "Post-PEPFAR" funding environment. We urge other care providers to share their ideas and experiences in sustaining services so that we can learn from best practices of others in maintaining and expanding quality HIV services in resource limited settings.

\section{Acknowledgements \\ We would like to thank the patients and staff of the Infectious Diseases Clinic, Kampala, Uganda.}

\section{Funding}

This work was funded by a grant to Dalhousie University by Grand Challenges Canada grant number 2078-01.

Availability of data and materials Not applicable. 


\section{Authors' contributions}

TK - background data collection, manuscript drafting, RPR - background data checking, manuscript review and revisions, WS, RB, AC - manuscript review and revisions. All authors read and approved the final manuscript.

\section{Authors' information}

TK is head of grants and strategic planning at IDI in Kampala. RPR is the immediate past head of clinical services at the Infectious Diseases Institute (IDI), Kampala, Uganda. RB is the current Executive Director of IDI and AC the immediate past ED. WS is a Professor of Infectious Diseases at Dalhousie University and has served as a visiting professor to IDI for over 10 years. The IDI has been involved in care and treatment of patients living with HIV since 2004 and is involved directly or indirectly in care for over $10 \%$ of all patients on HIV treatment in Uganda.

\section{Competing interests}

Rosalind Parkes-Ratanshi has received funding for consultancy for Janssen

Global Public Health. No other authors declare competing interests.

\section{Consent for publication}

Not applicable.

\section{Ethics approval and consent to participate}

Not applicable.

\section{Author details}

${ }^{1}$ Infectious Diseases Institute, Makerere University College of Health Sciences, PO Box 22418, Kampala, Uganda. ²Dalhousie University Faculty of Medicine, Nova Scotia, Canada.

\section{Received: 22 May 2015 Accepted: 23 August 2016}

Published online: 27 August 2016

\section{References}

1. Dieleman JL, Graves C, Johnson E, Templin T, Birger M, Hamavid H, Freeman M, Leach-Kemon K, Singh L, Haakenstad A, et al. Sources and Focus of Health Development Assistance, 1990-2014. JAMA. 2015; 313(23):2359-68.

2. UNAIDS THJKF. Financing the Response to HIV in Low- and Middle-Income Countries: International Assistance from Donor Governments in 2014. 2015. http://kff.org/global-health-policy/report/financing-the-response-to-aids-inlow-and-middle-income-countries-international-assistance-from-donorgovernments-in-2014/.

3. Amico P, Aran C, Avila C. HIV spending as a share of total health expenditure: an analysis of regional variation in a multi-country study. PLoS One. 2010;5(9):0012997

4. UNAIDS. Global report: UNAIDS report on the global AIDS epidemic 2013. In., vol. http://www.unaids.org/sites/default/files/media_asset/UNAIDS_ Global_Report_2013_en_1.pdf. Geneva: Joint United Nations Programme on HIV/AIDS (UNAIDS); 2013. p.198.

5. UNAIDS. Update on HIV treatment 2013: Results, Impact and Opportunities. In. Geneva: Joint United Nations Programme on HIV/AIDS; 2013.

6. WHO. The World Health Report: health systems financing: the path of universal coverage. In., vol. http://www.who.int/whr/2010/en/. Geneva: World Health Organization (2010); 2010. p.20.

7. Eaton JW, Menzies NA, Stover J, Cambiano V, Chindelevitch L, Cori A, Hontelez JA, Humair S, Kerr CC, Klein DJ, et al. Health benefits, costs, and cost-effectiveness of earlier eligibility for adult antiretroviral therapy and expanded treatment coverage: a combined analysis of 12 mathematical models. Lancet Global Health. 2014;2(1):e23-34.

8. Basaza RK, Criel B, Van der Stuyft P. Community health insurance amidst abolition of user fees in Uganda: the view from policy makers and health service managers. BMC Health Serv Res. 2010;10(33): 1472-6963

9. Health Mo: Statistical Abstract 2010. http://www.ubosorg/onlinefiles/ uploads/ubos/pdf\%20documents/PNSD/2010MOHStatAbstpdf 2010. Accessed 15 Dec 2015

10. Hecht R, Stover J, Bollinger L, Muhib F, Case K, de Ferranti D. Financing of HIV/AIDS programme scale-up in low-income and middle-income countries, 2009-31. Lancet. 2010;376(9748):1254-60.
11. UCBHFA. Strategic Plan for the Uganda Community Based Health Financing Association (UCBHFA) 2013/2014-2017/2018 In., vol. http://ucbhfa.org/wpcontent/uploads/2010/12/Strategic-Plan-.df_.pdf. Kampala: UCBHFA; 2013. p.29.

12. Basaza RK, O'Connell TS, Chapcakova I. Players and processes behind the national health insurance scheme: a case study of Uganda. BMC Health Serv Res. 2013;13(357):1472-6963.

13. Orem JN, Zikusooka CM. Health financing reform in Uganda: How equitable is the proposed National Health Insurance scheme? Int J Equity Health. 2010:9(23):1475-9276.

14. MOH. National Health Accounts FY 2008/09 and FY 2009/10 : general health accounts, reproductive health sub-accounts, and child health sub-accounts. Kampala: Ministry of Health; 2013. p. 79.

15. Rhoda K, Wanyenze GW, Alamo S, Amanyire G, Ouma J, Kwarisima D, Sunday P, Wabwire-Mangen F, Kamya M. Evaluation of the Efficiency of Patient Flow at Three HIV Clinics in Uganda. AIDS Patient Care STDs. 2010; 24(7):441-6.

16. WHO. Private health insurance: Implications for developing countries. 2004. Accessed 22 Dec 2015

17. Charlotte M, Zikusooka RK. Private medical pre-payment and insurance schemes in Uganda: What can the proposed SHI policy learn from them? EQUINET DISCUSSION PAPER 53. 2008. http://www.equinetafrica.org/sites/ default/files/uploads/documents/DIS53finZikusooka.pdf. Accessed 20 Dec 2015.

18. PEPFAR. Uganda Operational Plan Report. FY 2010. In., vol. http://www. pepfar.gov/documents/organization/145738.pdf. Kampala, Uganda: PEPFAR; 2010.

19. Coutinho A, Roxo U, Epino H, Muganzi A, Dorward E, Pick B. The expanding role of civil society in the global HIV/AIDS response: what has the President's Emergency Program For AIDS Relief's role been? J Acquir Immune Defic Syndr. 2012;60:152-157.

20. $\mathrm{MOH}$. Status report on the global fund grants in Uganda. In., vol. http:// www.health.go.ug/MoH/docs/global_fund.pdf. Kampala: Ministry of Health; 2011. p 32.

21. Globalfund. New Funding Model: Eligibility, Counterpart Financing and Prioritization Policy Revision. In: Thirtieth Board Meeting GF/B30/6 7-8 November 2013 2013. Geneva, Switzerland: Global Fund; 2013.

22. MOF. Poverty Status Report (PSR) 2012. 2012

23. Health UMo. AIDS Indicator Survey. 2011. hppt://healthgoug/docs/UAIS 2011 REPORTpdf, Accessed 12 May 2015.

24. USAID. AIDSTAR-One Project: Private Sector Involvement in HIV. 2009. http:// pdf.usaid.gov/pdf_docs/pnaea053.pdf. Accessed 20 Dec 2015.

25. Project UA. Assessment of quality of ART services in the private sector in Uganda. 2009. https://www.usaidassist.org/resources/assessment-quality-artservices-private-sector-uganda. Accessed 20 Dec 2015.

26. Burnham GM, Pariyo G, Galiwango E, Wabwire-Mangen F. Discontinuation of cost sharing in Uganda. Bull World Health Organ. 2004;82(3):187-95.

27. Byakika-Tusiime J, Oyugi JH, Tumwikirize WA, Katabira ET, Mugyenyi PN, Bangsberg DR. Adherence to HIV antiretroviral therapy in HIV+ Ugandan patients purchasing therapy. Int J STD AIDS. 2005;16(1):38-41.

28. Alsan M, Schoemaker L, Eggleston K, Kammili N, Kolli P, Bhattacharya J. Outof-pocket health expenditures and antimicrobial resistance in low-income and middle-income countries: an economic analysis. Lancet Infect Dis. 2015; 15(10):1203-10.

29. Adelline T, King R, Schlech WF, Faridah M, Kakaire T, Rosalind ParkesRatanshi P. Exploring Attitudes and Perceptions of Patients and Staff Towards a Fee For Service "After Hours" Clinic Supplementing Free Hiv Services in Uganda: A Qualitative Study. Value Health. 2015:18(7):A590.

30. Parkes-Ratanshi R, Mukisa G, Kakaire T, Mayanja F, Tumikye A, Mitchell B, Nakalema S, Schlech W. Characteristics and outcomes of patients seeking care at a new "co-pay" convenience clinic established to explore sustainable funding models in Uganda. In: Conference on Retroviruses and Opportunistic Infections February 23-26, Seattle, Washington; 2015. Available at http://www.croiconference.org/sessions/characteristics-and-outcomespatients-seeking-care-new-\%E2\%80\%9Cco-pay\%E2\%80\%9D\%C2\%9Dconvenience-clinic.

31. Gilson L. The lessons of user fee experience in Africa. Health Policy Plan. 1997;12(4):273-85. 